Portland State University

PDXScholar

$9-1-2010$

\title{
Community-Based Approaches to Reduce Toxins in Housing: Lessons Learned from Working with Diverse Communities
}

\author{
Erin McNally \\ Ian Blazina \\ Portland State University \\ Stephanie Farquhar \\ Portland State University
}

Follow this and additional works at: https://pdxscholar.library.pdx.edu/commhealth_fac

Part of the Community-Based Research Commons, and the Community Health and Preventive Medicine Commons

Let us know how access to this document benefits you.

\section{Citation Details}

McNally, E., Blazina, I., \& Farquhar, S. A. (2010). Community-Based Approaches to Reduce Toxins in Housing: Lessons Learned From Working with Diverse Communities. Environmental Justice (19394071), 3(3), 85-93.

This Article is brought to you for free and open access. It has been accepted for inclusion in Community Health Faculty Publications and Presentations by an authorized administrator of PDXScholar. Please contact us if we can make this document more accessible: pdxscholar@pdx.edu. 


\title{
Community-Based Approaches to Reduce Toxins in Housing: Lessons Learned From Working with Diverse Communities
}

\author{
Erin McNally, Ian Blazina, and Stephanie A. Farquhar
}

\begin{abstract}
This article will review lessons learned from a community-based participatory research project with Latino and Somali residents in Portland, Oregon. The aim of the Healthy Futures Collaborative (HFC) project was to reduce in-home environmental health hazards associated with childhood respiratory illness and asthma through a process that strengthened social support and civic engagement. Using a communitybased approach, the HFC trained community residents as community scientists to ensure local leadership and participation. Results suggest an increase in Somali and Latino residents' knowledge of environmental stressors and changes in behavior that may improve indoor environmental quality.

Especially when working with historically marginalized communities, a model that acknowledges power differentials and responds to community-identified priorities is a powerful model for addressing environmental injustices. For example, the project was able to address both behavioral and structural components of housing and poor indoor environmental quality by providing workshops on green cleaning and tenants' rights. Yet, the participatory structure presents unique challenges-including issues of representation and distributive justice-challenges that may be exacerbated in cross-cultural projects with multiple racial/ethnic groups.
\end{abstract}

\section{INTRODUCTION}

$\mathbf{T}$ HIS ARTICLE DOCUMENTS ACTIVITIES of a communitybased participatory research (CBPR) project that included asthma-related home health assessments and tailored in-home interventions with Latino and Somali residents. Principally, issues surrounding recruitment and training of community leaders, designing culturally competent assessments and interventions, and increasing social capital and community engagement warrant further discussion in the public health and environmental justice literature. The authors describe lessons learned that may be of use to other organizations seeking to address environmental health issues from a communitybased perspective.

Ms. McNally is Executive Director of Josiah Hill III Clinic in Portland, OR. Mr. Blazina is at Portland State University, School of Community Health. Dr. Farquhar is Assistant Professor of Community Health at Portland State University.

\section{Literature review}

Inadequate housing and poor indoor air quality are increasingly recognized as public health crises (Bashir 2002; Institute of Medicine 2004; Institute of Medicine 2000; Krieger 2002; Matte and Jacobs 2000). Since people in North America spend most of their lives indoors (Hancock 2002), interventions focused on improving housing conditions have the potential to reduce prevalence of chronic diseases including asthma (Thomson et al. 2001; Institute of Medicine 2000). Asthma, the leading cause of hospitalization and school absenteeism among inner-city children in North American cities (Wissow et al. 1998), is largely mediated by air quality in the built environment (Institute of Medicine 2000; Custovic et al. 2001).

Interventions involving simple and cost-effective cleaning procedures have been shown to reduce allergen exposure (Carter et al. 2001; Adgate et al. 2008). Green cleaning is the use of cleaners with lower toxicity and has been associated with decreased incidence of wheezing and respiratory problems in preschool aged children (Sherriff 
et al. 2005. The U.S. Department of Housing and Urban Development's Healthy Homes Initiative promotes home assessments to monitor airborne allergen exposure, training and assistance in affordable remediation efforts, local capacity building, public education, and housing advocacy. The Healthy Homes Initiative is one example among several promising models that jointly addresses inadequate housing, poor indoor air quality, and the high prevalence of asthma (U.S. HUD 2008).

Aligned with the goals of the Healthy Homes Initiative and recommendations from the National Institute of Environmental Health Sciences, a community-based approach to addressing indoor air and environmental quality issues improves community partnerships by building social capital and fostering interaction among residents (Srinivasan et al. 2003; O'Fallon and Dearry 2002). This approach acknowledges power differentials, responds to community needs, and seeks to empower community (Israel et al. 1998). Yet, the community-based participatory research structure presents unique challenges of representation and distributive justice that are exacerbated in cross-cultural projects in which multiple ethnic groups are involved. These difficulties include issues of soliciting and authentically conveying the broad spectrum of community concerns and attempting to fairly distribute the benefits of the project across the community. For projects involving Latino and Somali populations, several factors have been identified as necessary for these types of community-based interventions. These include education provided in the participants' primary language, recruitment of staff from within communities, and broad leadership training and support ( $\mathrm{O}^{\prime} \mathrm{Neil}$ et al. 2008; Farquhar et al. 2008).

\section{METHODS}

\section{Background}

In 2002 through 2005, the Multnomah County Health Department led a community-based assessment utilizing a guidance tool developed by environmental health professionals and the Centers for Disease Control and Prevention (CDC), the "Protocol for Assessing Community Excellence in Environmental Health" (PACE-EH) tool. Based on available data showing environmental hazards as well as health impacts, paired with a stated interest from community residents for further assessment and actions, five priority communities were identified in Multnomah County, Oregon. These Portland communities included: Inner North/Northeast, East County/ Rockwood, St. Johns/Peninsula, Cully/Outer Northeast, and Lents/Outer Southeast.

The Cully neighborhood of Northeast Portland was identified in the PACE-EH process as one of the environmental justice communities that had a significant proportion of low-income immigrant populations and persons of color, and borne more health-threatening environmental exposures than other communities in Multnomah County. Moreover, the diverse neighborhood was one in which residents often felt ignored or underrepresented. For these reasons, the Cully neighborhood was seen as a promising choice for a community-based project aimed at increasing representation of marginalized people and enacting distributive justice in a community that has historically borne an unequal burden of environmental hazards.

Between the 1990 and 2000 census, the Hispanic population grew five-fold in this neighborhood. The majority of residents was of low socioeconomic status, with $85 \%$ of the students at the local elementary school qualifying for free or reduced lunch. In recent years, the Cully neighborhood has grown more culturally and ethnically diverse as new populations such as the Somali Bantu moved into the community. At community gatherings, residents verbally expressed a sense of tension and cultural isolation arising from the differences between tenants and home owners, as well as the differences between ethnic groups. Josiah Hill III Clinic (JHC), the primary partner in this project, had a history of focusing efforts within the Cully neighborhood, and had established a high level of rapport and trust with residents. JHC chose to focus the community-based participatory research project, the Healthy Futures Collaborative, in this neighborhood because of JHC's history with this community and results from the PACE-EH neighborhood selection process.

\section{Healthy futures collaborative}

The aim of the Healthy Futures Collaborative (HFC) was to identify and address in-home environmental health hazards associated with childhood respiratory illness and asthma through a process that would strengthen neighborhood protective factors such as social support, civic engagement, and community capacity. To achieve this aim, the HFC engaged and trained community residents as community scientists to ensure community leadership and participation, conducted baseline and post intervention in-home assessments, and provided information and resources as requested by the community. Through a collaborative community-based process, the HFC worked to increase residents' knowledge of environmental stressors related to asthma, knowledge of services and resources, and reduce exposures to these stressors.

The range of community and agency partners involved in the HFC project contributed to its success. Josiah Hill III Clinic provides direct healthy homes services to families and advocates for healthy housing policies in the Portland, Oregon metro area. Other primary project partners included Portland State University's School of Community Health, Multnomah County's Environmental Health Section, Lutheran Community Services Northwest, Somali Maay Community Organization of Oregon, METRO Regional Government, Somali and Latino community residents.

\section{Recruiting and training community scientists}

In order to employ a community-based process, it was imperative to identify, recruit, and support leaders from the community throughout the project. Josiah Hill III Clinic solicited input from community-based organizations and programs which served the community, attended 
community meetings held in the neighborhood, led focus groups with each cultural group, and received input from community members. The aim of the discussions was to listen to perspectives and priorities around health and housing, receive feedback about culturally competent ways to provide home health assessments and education, and to invite others to become involved with the Healthy Futures Collaborative project. Further, JHC spoke directly to families in the community either at parenting and support classes or simply while attending neighborhood events and fairs.

The initial recruitment approach was similar in the Somali and Latino communities. However, it became clear that the cultural norms and communication styles were different; as a result, recruitment was tailored for appropriateness in both communities. Access to community leaders in the Latino community was facilitated by more clearly defined leadership and Latino community members felt empowered to join the project and be a voice for their community. Also, JHC had a history of working with Latino families in the neighborhood and was more aware of individuals with whom to connect. In the Somali community there were a few key individuals who were influential with the community at large. Visits to the Somali families were made with one of these Somali community leaders and were predominately conducted by female community scientists to respect the Muslim faith and cultural norms of the Somali Bantu families the project recruited which discouraged social interaction between unrelated men and women when they are alone; therefore impacting access for home assessments. Furthermore, when working with Somali Bantu populations issues regarding respectful treatment of Somali religious and cultural customs were considered, including genderspecific roles.

\section{Community trainings and community scientists}

The HFC trained a diverse group of community leaders that could act as conduits between the community and the greater Collaborative. Community leaders were identified through volunteer, community, and intern networks. Further, individuals from the neighborhood who were eager to have a larger leadership role in the Collaborative were invited to become community scientists. Community scientists were responsible for attending training, providing education, and completing a minimum number of home health assessments. Community scientists were volunteers, however, six lead community scientists received stipends. The lead community scientists took leadership in completing a larger number of home assessments and were representative of the study participants as they were all low-income Latino and Somali residents from the neighborhood. By engaging bilingual and bicultural community leaders as community scientists, the HFC was able to involve individuals who were the same race and ethnicity of the community and who were able communicate in the same language and were familiar with styles of communicating and ways of interacting. Bilingual and bicultural leaders spoke either English/Spanish or English/Somali Maay and self- identified as someone who was born in Mexico or Somalia and now lived in the U.S. Being bilingual was not a requirement to become a community leader, in fact some community leaders only spoke their native language such as Spanish. The use of community scientists increased the representation among the participating communities by actively engaging them in the research process.

The trainings were co-developed and co-facilitated with the community partners and community leaders. The training included topics such as community-based participatory research, in-home asthma triggers, indoor air and environmental quality, environmental justice, cultural competency, and completing home health assessments with a family-centric approach that attempted to involve all family members. Community leaders and providers shared information and materials were provided in multiple languages. The second training was conducted in three languages with real-time interpretation for Somali Maay and Spanish, further strengthening the role of the community members in the research process.

\section{Study recruitment and home health assessments}

Oregon asthma hospitalization rates in 2004 stratified by age showing the highest rates in children less than five years old and among adults greater than eighty years old (Oregon Asthma Program 2006). Thus, recruitment occurred with families with children and/or pregnant women. The HFC identified Latino and Somali families with children and/or women who were pregnant.

Using reputational sampling methods JHC recruited community members through existing channels, such as parenting groups at the local community center, community meetings, health fairs, JHC's mobile lead testing clinics, and similar events. Reputational sampling, also called "snowball sampling," is a widely used nonprobability sampling technique that is employed when randomized sampling processes are not feasible, or when successful recruitment requires that there is a high level of trust and familiarity among participants (Etter and Perneger 2000). Using this method, the interviewer identifies families that possess the demographic and other characteristics appropriate to the study question. The interview respondents are then asked to recommend other families who may be interested in participating in the project.

Data were collected from 71 households in the Cully neighborhood using a Healthy Home Assessment Questionnaire. To assess impact of the intervention activities on study outcomes of interest, the same pre/post questionnaire was administered at baseline, and again at one year. In order to be eligible for post assessment, households needed to participate in at least one intervention activity. Further, due to the mobility of the community, it was determined to follow-up with participants who were living in the same household to ensure the environment was as similar as possible. The goal was to retain at least 35 (approximately 50\%) of participants for the follow-up. Post questionnaires were administered to 37 families $(53 \%)$ that participated in the intervention, 27 Latino households and 10 Somali households. 
JHC staff and community scientists completed the initial home health assessments with families. The purpose of the home assessments was to work with families to identify potential in-home asthma triggers, gather information on awareness of household asthma triggers, knowledge of current community resources, and level of existing social capital-defined here as networks and social trust that facilitate neighbors' cooperation for mutual benefit (Putnam 2000). Further, the HFC received feedback from families on desired next action steps related to asthma and improving the indoor environmental quality. The assessment measured behavioral and structural factors that could contribute to in-home health hazards, including ventilation, presence of mold, necessary repairs, and cleaning practices. Questionnaires were administered verbally with community scientists recording responses while walking through the house with the family member.

\section{RESULTS}

A total of 71 baseline home health assessments were completed, with $76 \%(\mathrm{n}=54)$ Latino families and $24 \%$ $(n=17)$ Somali families. Approximately $86.5 \%$ of the respondents were renters. Nearly all households (95\%) reported having at least one child under the age of 12 in the household, while $2.7 \%$ of the household's children did not have health insurance and $83.8 \%$ of household's children were insured through the Oregon Health Plan. The Oregon Health Plan $(\mathrm{OHP})$ provides health care coverage to eligible low-income Oregonians through programs administered by the Division of Medical Assistance Programs.
Data from the pre- and post-intervention surveys suggest that while similarities existed, Somali and Latino families had different perspectives and priorities. When asked "I have attended a community event in the last 6 months," approximately $62 \%$ of respondents $(74 \%$ of Latino and $30 \%$ of Somali respondents) stated they had attended a community event in the last six months in the pre-intervention questionnaires. However, in the postintervention questionnaire, this total figure increased to $81 \%$ of the respondents. When asked "I am aware of health resources available to me and my family," of the $54 \%$ of all respondents reported they somewhat agreed/ strongly agreed with the statement, $8.1 \%$ were Somali while $46 \%$ were Latino (pre-intervention). After the intervention, $92 \%$ of all respondents somewhat agreed/ strongly agreed with the same statement (see Figure 1).

Somali home assessment respondents expressed a desire for information on tenants' rights $(88 \%)$, lead prevention $(88 \%)$, and green cleaning $(75 \%)$, while Latino respondents predominately expressed interest in green cleaning $(80 \%)$ with lesser interest in other areas. Because Josiah Hill III Clinic already performs lead prevention tasks in the neighborhood, project partners agreed to highlight the existing lead services and provide trainings regarding green cleaning and tenants' rights for both communities, but with differing primary foci depending on the community-identified interests. Information on green cleaning and tenants' rights were included together in one training for participant convenience. By providing trainings on green cleaning and tenants' rights, the HFC was able to address both behavioral and structural

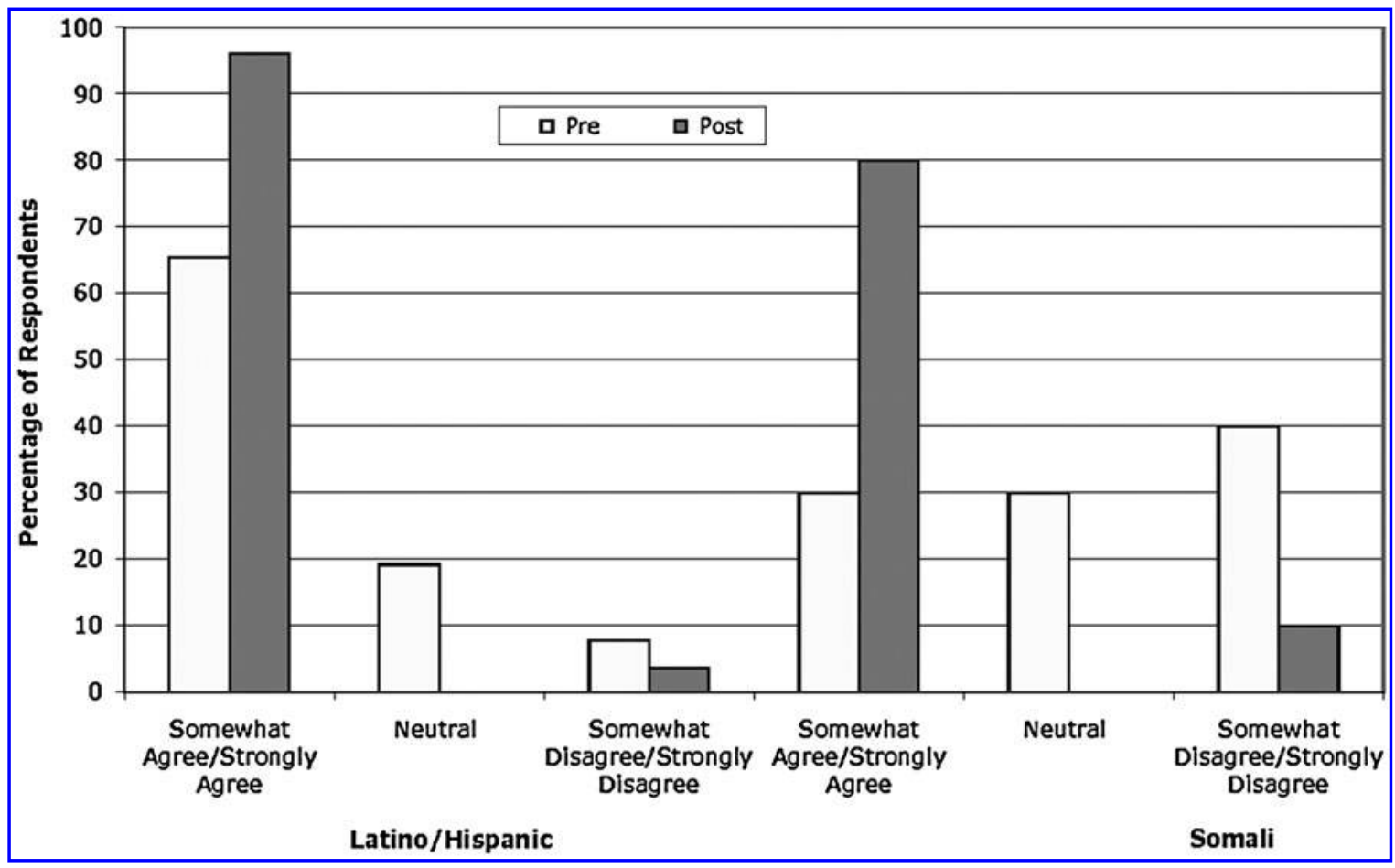

FIG. 1. Survey Question: I am aware of health resources available to me and my family. 


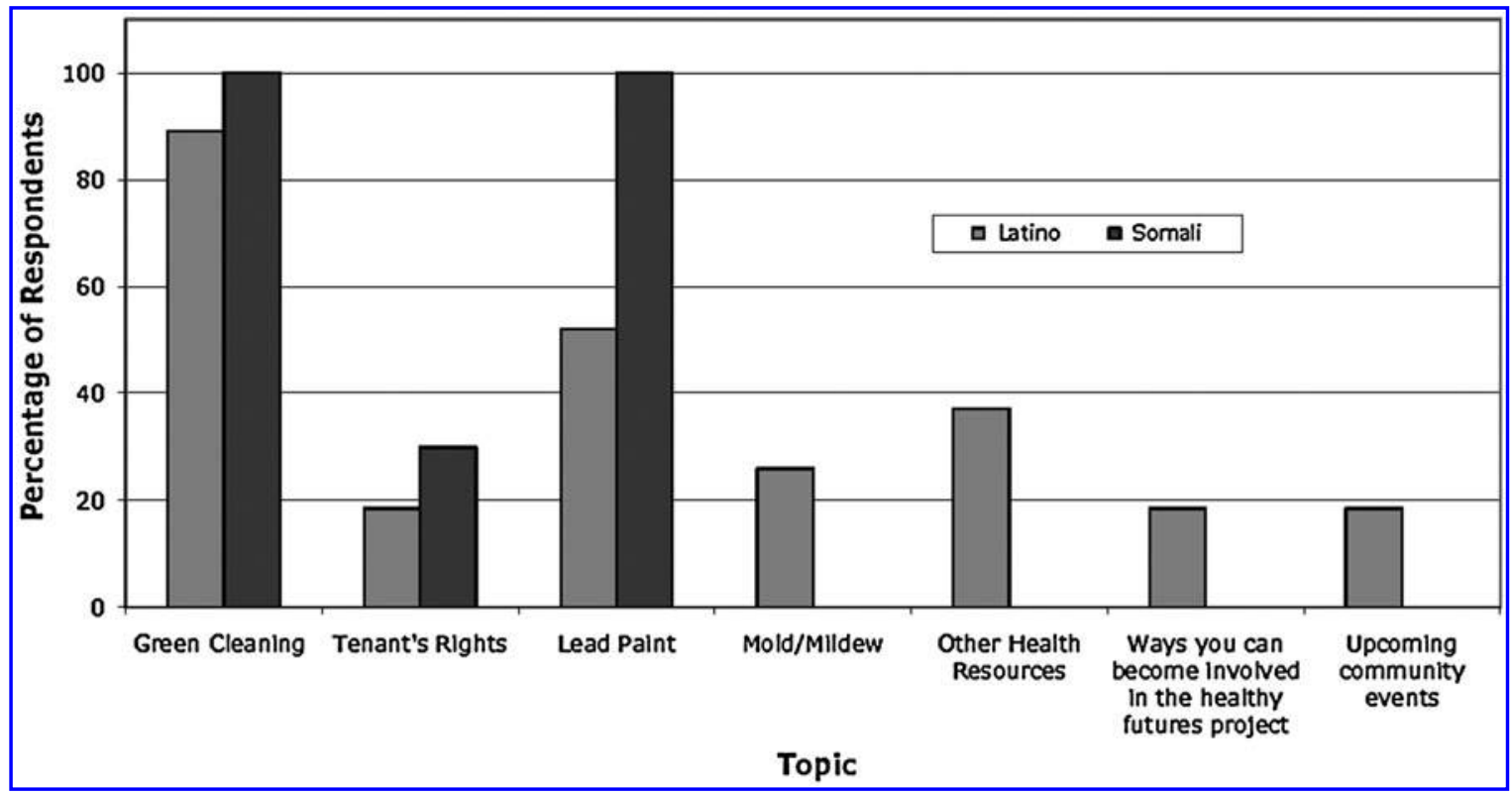

FIG. 2. Which of the following did you learn more about and/or receive resources?

components which may impact the air quality of indoor environments.

One of our project partners, METRO Regional Government's Waste Reduction and Outreach program, provided an in-kind donation of 75 green cleaning kits. Each kit allowed for training participants to make: a multi-purpose cleanser, a window cleaner, and a tub/tile cleaner. METRO trained one staff member and three Latino community scientists to conduct green cleaning workshops. JHC staff in turn trained Somali leaders. After the intervention, respondents reported learning about or receiving resources related to green cleaning, tenants' rights, and lead paint (see Figure 2).

The increase in knowledge and resources regarding green cleaning illustrated in Figure 2, is further reflected in changes in green cleaning behavior among respondents in Figure 3. Both the Latino and Somali households reported an increase in their use of green cleaning products such as baking soda and vinegar in the post-intervention questionnaire (see Figure 3). There was a decline in the number

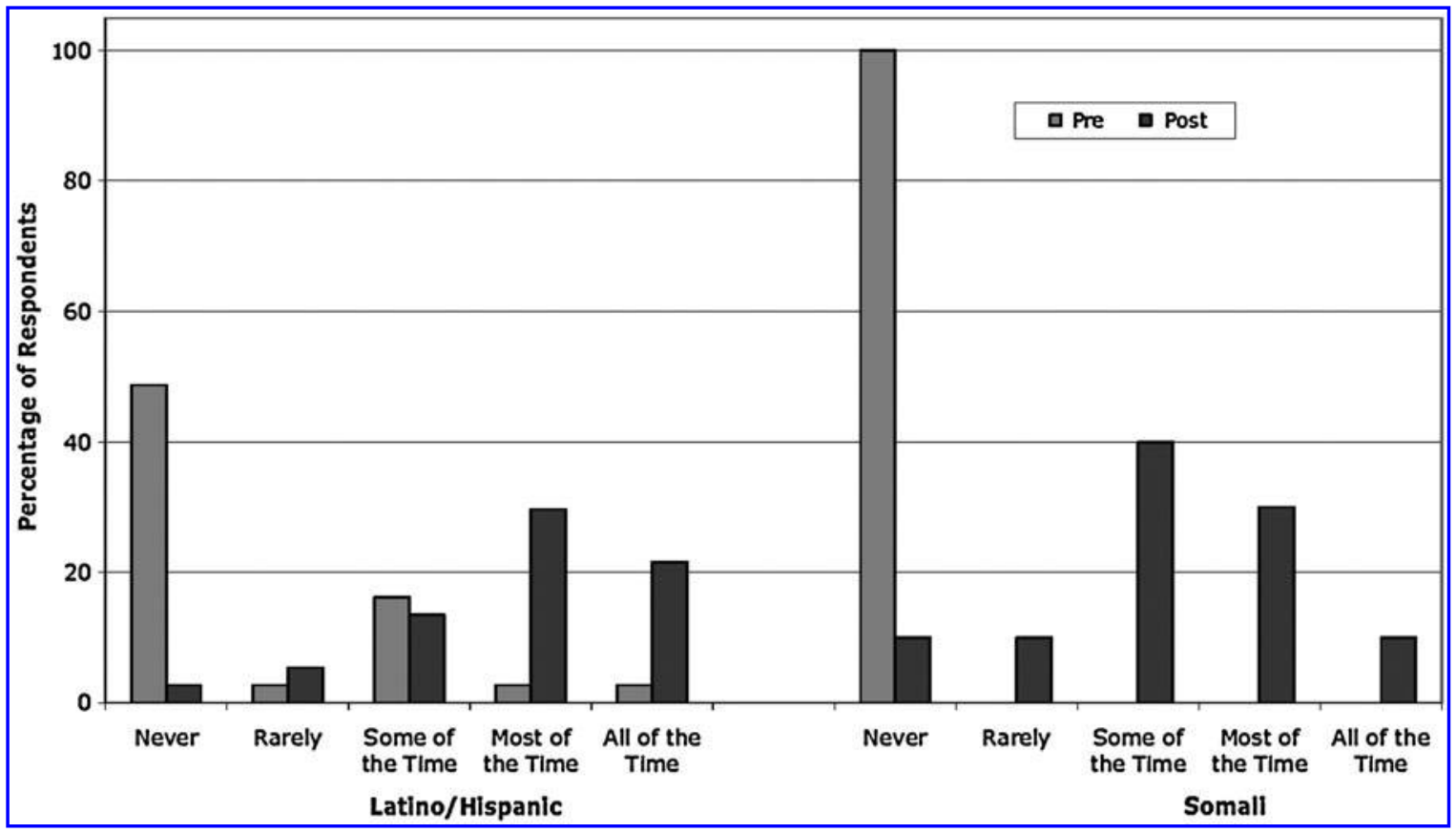

FIG. 3. How often do you use green cleaning products such as baking soda, vinegar, etc? 
of respondents who reported "never" using greener cleaning products in the post-intervention questionnaire, which suggests adoption of less toxic cleaning methods. This shift was paralleled by a reduction in the use of chemical cleaning products over the course of the intervention.

\section{Household interventions and cultural competency}

To ensure the green cleaning trainings were culturally appropriate for the families the project served, the community scientists and project partners provided feedback and suggestions to METRO and the HFC. In response, cleaner recipes and training materials were revised and incorporated pictorial recipes and limited written instruction, as shown in Figure 4. A "train the trainer" model was employed, with those who were trained then training others, including more Latino and Somali residents.

JHC involved partners to assist with tenants' rights trainings, seeking to empower residents to take advantage of their housing rights regardless of perceived or enacted barriers that may inhibit representation and to understand and exert their rights. The Community Alliance of Tenants (CAT) provided training on renters' rights to Somali community scientists and JHC staff. JHC and community leaders worked with CAT to develop a culturally appropriate tenants' rights presentation for Somali residents. Rather than providing a written manual on tenants' rights, scenarios were developed and presented verbally in small groups at the training. CAT volunteers delivered the training to Somali residents with interpretation provided by the community scientists. An overview of green cleaning and cleaning kits were provided at the same workshop.

At the trainings, the HFC families inquired to the possibility of an on-site mini-healthy homes fair which would be open to the neighborhood at large and would be culturally appropriate and accessible for families. The HFC organized a mini-fair along with partners and residents, which was held on-site at the main affordable housing apartment complex. Services provided at the fair included lead poisoning prevention workshops, blood lead testing, green cleaning workshops, tenants' rights workshops, information and referral for toxin reduction, and healthy homes. Community leaders assisted with outreach, canvassing, interpreting, leading workshops, and general facilitation. There were on-site interpreters and education was provided verbally and pictorially. Ninety community members participated in the fair.

Approximately $60 \%$ of families which received an initial home health assessment attended both the green cleaning and tenants' right trainings. Of these families, nearly $40 \%$ attended an additional lead poisoning prevention workshop. Further, many more families were reached and received healthy homes resources at outreach events and through the healthy homes mini-fair which did not receive an initial home health assessment. Prior to entering the intervention, $57 \%$ of participating households agreed or strongly agreed with the statement "the services I receive are culturally appropriate and respectful." This percentage increased to $89 \%$ of respondents after receiving the intervention.

Figure 5 demonstrates an increase in the languageappropriate services from pre- to post-intervention questionnaires which serves to represent a principal component of culturally appropriate and respectful service delivery. Figure 5 also presents a complementary decrease in those who initially reported "neutral" or "disagree."

\section{Lessons learned}

Numerous lessons were learned during this CBPR project which may be applicable to other cross-cultural

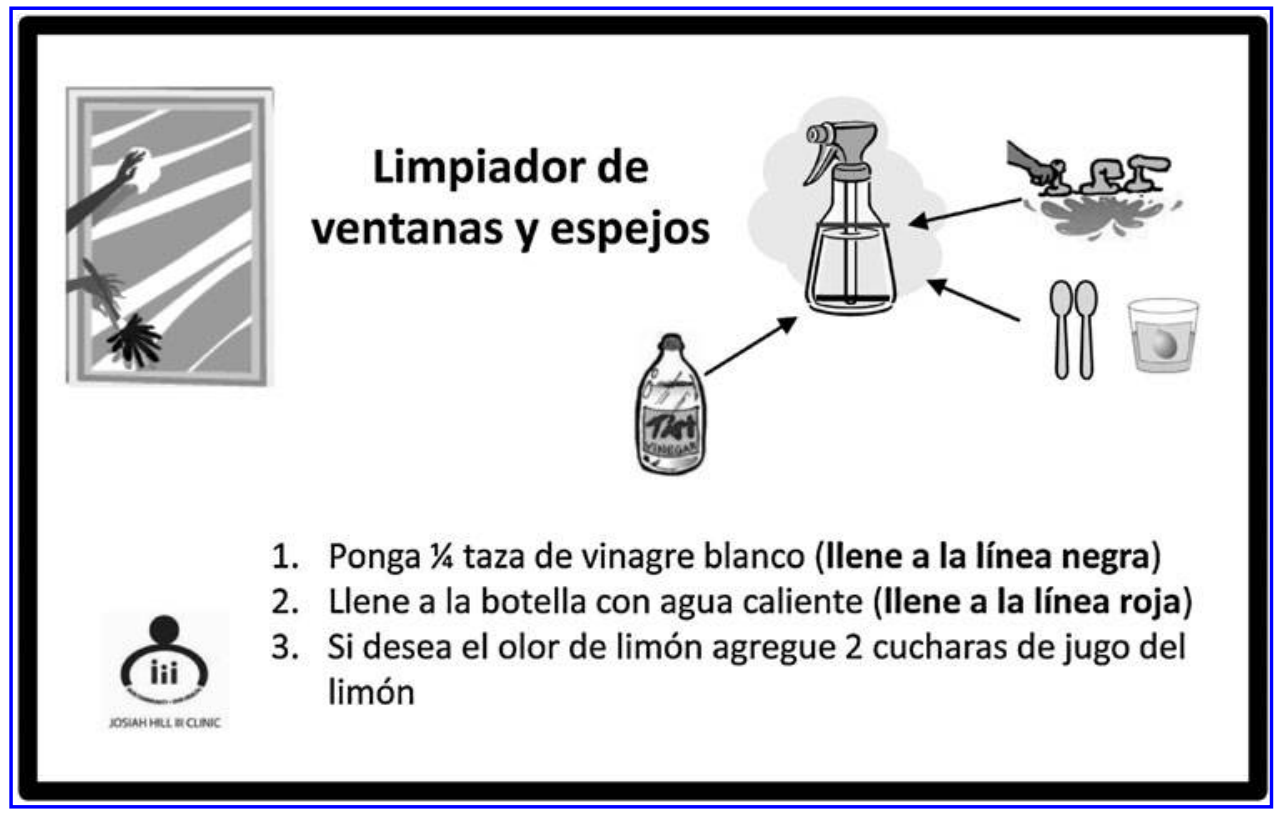

FIG. 4. Sample training materials incorporating pictorial recipes and limited written instruction. 


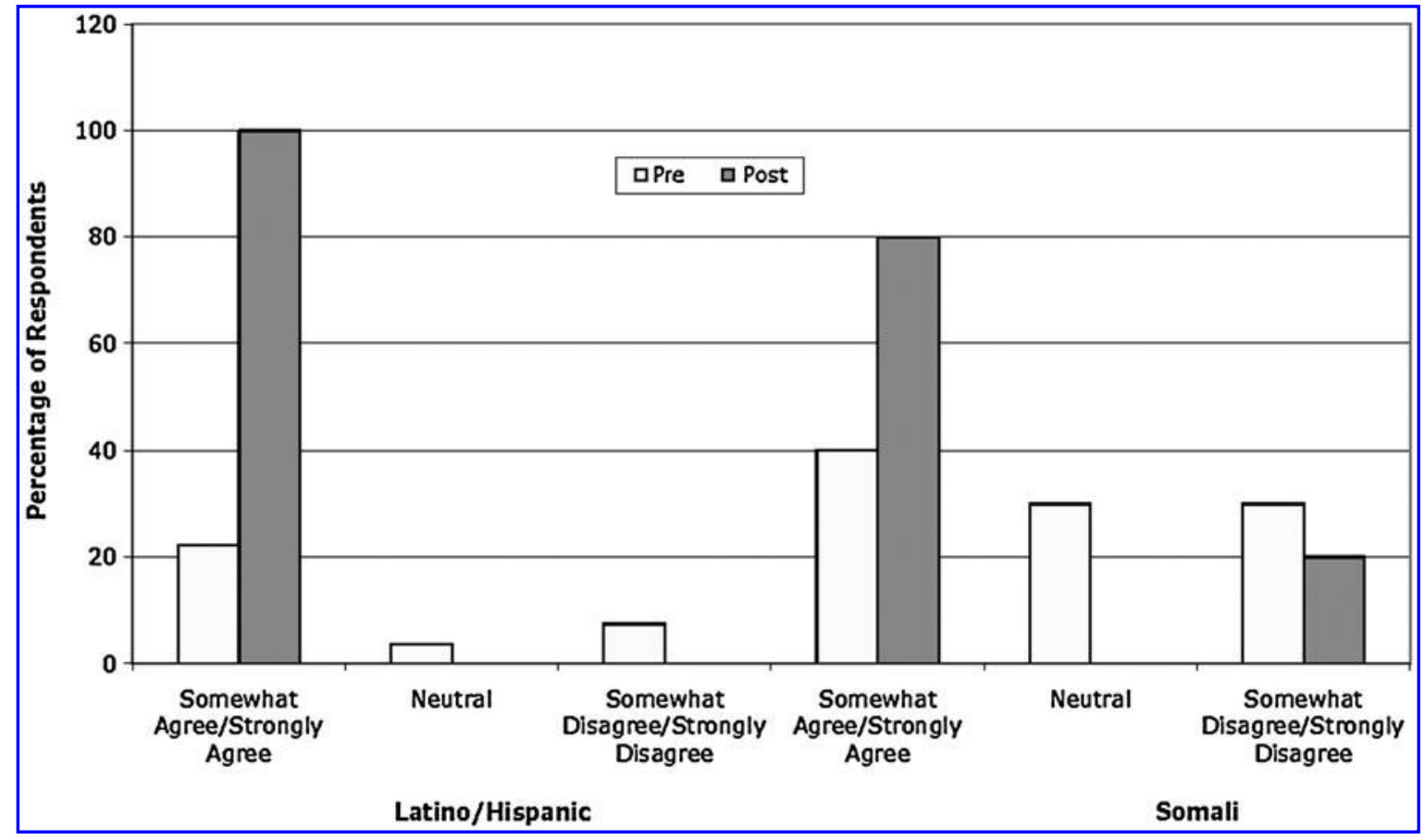

FIG. 5. Survey Question: The services I receive are in my language.

research initiatives. Taking the time to conduct initial focus groups and feedback sessions in order to learn about cultural and religious norms within the community aided the HFC in tailoring outreach and home assessments in a culturally appropriate manner. For example, home health assessments were scheduled during times convenient for families and acknowledged observances of prayer times and religious holidays such as Christmas and Ramadan. Home health assessments were administered verbally and in person to acknowledge that some cultures prefer to communicate orally rather than in writing, and that literacy levels varied among participants. Further, by visiting the participating families we were able to provide and collect information in the family's primary language.

Engaging community leaders and training them as community scientists was imperative to the success of the project. Levels of trust and rapport among the community scientists and the neighborhood residents increased, and recruitment of households to participate in the study was much quicker than anticipated. Further, the active participation of the community scientists allowed JHC to provide project information, health education, and trainings in the Somali Maay or Spanish language and through culturally appropriate communication styles. Understanding language barriers and cultural communication styles was a crucial step towards increasing representation among participants and engaging participants in order to begin to redistribute the unequal power relations resulting from communication barriers.

One strategy which aided in the development of social cohesion among the diverse communities was to hold meetings with simultaneous, real-time interpretation so community members could share information. By bring- ing residents together to listen to one another, interaction increased and power was shared within this facilitated setting. Although the meetings took longer, it was important to the HFC and residents to unify the communities rather than hold separate meetings, fostering intercultural interaction among neighbors.

There were also many challenges encountered throughout the project. Many of the challenges stemmed from the lack of knowledge and experience of the lead agency and partner groups in working with the Somali Bantu families. Prior to beginning this project, the partners acknowledged this deficiency but agreed that this was an opportunity to learn about the different priorities and communication styles of the Somali and Latino communities. To address this lack of experience, HFC engaged a partner agency that worked closely with the Somali refugee community and engaged key Somali Bantu leaders. Although engaging the agency and key leaders was informative, the overall challenges brings forward the question as to whether a research project was the appropriate venue to develop the organizations' knowledge and experiences working with these diverse communities or if a focus on organizational program development and delivery should have occurred prior to research being conducted. Before implementing future CBPR projects an honest discussion regarding capacity and experiential knowledge with the partner community and among project partners should occur.

As mentioned previously, after conducting the baseline home assessments and analyzing data, it became evident that the two communities had different priorities regarding green cleaning and tenants' rights. This posed a challenge as the HFC initially thought the chosen intervention would be the intervention with the most overall 
interest among households, however two distinct preferences were obvious. The Collaborative could have chosen to move forward with the top overall intervention but felt this would not adequately address the stated interest of the Somali community, resulting in a potential reduction in study retention and also a reduction in the trust and rapport the HFC worked hard to establish. Rather than one intervention, the HFC chose to develop two interventions, with both a primary and secondary focus, to ensure each community had their desires met. The addition of tenants' rights trainings was intended to engage a wide range of community members and to develop tools that would allow participants to work towards distributive justice in their neighborhood. Developing two interventions took more resources and stretched the capacity of the lead organization. One way to overcome this challenge in future projects would be to recruit an equal number of Latino households and Somali Bantu households so that the selected intervention components would have a greater chance of representing the desires of both communities. Project partners may also anticipate the need for more than one intervention and should adjust the timeline and allocate project resources accordingly.

Another challenge of working with two communities was that many providers had substantial experience working with the Latino community but limited experience with the Somali Bantu community. Therefore, there is a lack of culturally appropriate programs and resources for the Somali Bantu families. This posed challenges to both the intervention portion of the project as well as challenges when working with partners to develop culturally appropriate programs. First, the availability of resources for the intervention for Latino families but not for Somali families was a unique challenge in that, if the resources were provided as available, the Latino families would receive intervention resources well in advance of the Somali families. However, in order to provide intervention resources at the same time, and for the participants to be optimally represented in the research process, time was needed to develop culturally appropriate interventions for the Somali Bantu families. The Collaborative chose the latter for this project as it was important to the Collaborative that the community scientists and the HFC allow the time necessary to develop culturally appropriate interventions such as the creation of pictorial green cleaning recipes, and the development of trainings that could be shared verbally with stories or scenarios. Some of the families that participated in the home health assessments were frustrated with the lag time between the baseline home health assessment and the intervention resources. JHC and HFC partners listened to this feedback and worked to develop the resources as quickly as possible to minimize this lag time. The HFC hoped to reduce this frustration by communicating the time frame for interventions during the home assessments. However, the HFC could have explored and developed ways in which to engage households in the project during the time between the home assessment and the intervention. Second, there was a challenge posed that the lead agency needed to encourage partners to develop culturally appropriate resources which were not currently available. Needing to develop new educational materials and/or ways in which to deliver services stretched some partners' resources. JHC attempted to assist in this challenge by encouraging partners to utilize community leaders to offer feedback on ways to tailor materials and services so they were more culturally appropriate and also by offering to pay for interpreters. The authors also acknowledge that the use of reputational sampling may decrease the ability to generalize the study results to other Somali or Latino communities.

\section{CONCLUSION}

Using a community-based participatory research framework, the present study offers further evidence of the success of the approach in improving the built environment and strengthening communication and partnerships (Srinivasan et al. 2003; O'Fallon and Dearry 2002). In accordance with research demonstrating the effectiveness of green cleaning procedures in reducing allergen exposure (Carter et al. 2001; Adgate et al. 2008), a decrease in particulate matter and chemical pollutants was observed, and adoption of green cleaning methods was promising. Most importantly, the use of in-language educational materials, recruitment of staff from within the communities, and strong leadership training and support (O'Neil et al. 2008) resulted in increased awareness of available health resources, a desire for more health information, and culturally appropriate information delivery. Differences in preferred method of information delivery (textual, pictorial, or oral), information content, and interaction style may be helpful in designing interventions tailored to Latino and Somali Bantu populations.

\section{ACKNOWLEDGMENTS}

Thank you to the Northwest Health Foundation, the primary funder of the Healthy Futures Collaborative. Additionally, we would like to thank Providence Health and Services and Portland State University for their financial support as well as Metro Regional Government, AmeriCorps LINKS, and AirAdvice for providing in-kind support. Staff, volunteers, contractors, community scientists, and interns were instrumental in every step of the project and included Natalie Sampson, Erica Sandoval, Jessica Kendall, Samantha Kaan, Catherine GonzalezMaddux, Carma Corcoran, Laura Krane, Maria Garcia, Leslie Caldaron, Claudia Pulido, Carmela Pulido, Muktar Abdow, Faiza Abu, Halimo Amin, and Lul Abdulle. The Healthy Futures Collaborative advisory group helped guide the project and provide collaborative resources for families. Thank you to Ben Duncan, Pierre Morin, and Lisa Heigh for your leadership.

\section{AUTHOR DISCLOSURE STATEMENT}

The authors have no conflicts of interest or financial ties to disclose. 


\section{REFERENCES}

Samiya A. Bashir, "Home Is Where the Harm Is: Inadequate Housing as a Public Health Crisis," American Journal of Public Health 92 (May 2002): 733-738.

Institute of Medicine. Damp Indoor Spaces and Health. (National Academies Press, 2004).

Institute of Medicine. Clearing the Air: Asthma and Indoor Air Exposure. (National Academies Press, 2000).

J. Krieger, "Housing and health: time again for public health action," American Journal of Public Health 92 (2002): 758-768.

T.D. Matte and D.E. Jacobs, "Housing and health: current issues and implications for research and programs," Journal of Urban Health 77 (2000): 7-25.

Trevor Hancock. "Indicators of Environmental Health in the Urban Setting," Canadian Journal of Public Health 93 (Sep 2002): 45-51.

Hilary Thomson, Mark Petticrew, and David Morrison. "Health Effects of Housing Improvement: Systematic Review of Intervention Studies," British Medical Journal 323 (July 2001): 187-190.

Lawrence S. Wissow, Alan M. Gittelsohn, Moyses Szklu, Barbara Starfield, and Mary Mussman, "Poverty, Race, and Hospitalization for Childhood Asthma," American Journal of Public Health 78 (Jul 1998): 777-782.

A. Custovic and A. Woodcock. "On Allergens and Asthma (Again): Does Exposure to Allergens in Homes Exacerbate Asthma?," Clinical \& Experimental Allergy 31 (May 2001): 670-673.

Melody C. Carter, Matthew S. Perzanowski, Amos Raymond, and Thomas A. E. Platts-Mills, "Home Intervention in the Treatment of Asthma Among Inner-City Children," Lournal of Allergy and Clinical Immunology 108 (Nov 2001): 732-737.

John L. Adgate, Gurumurthy Ramachandran, Sook J. Cho, Andrew D. Ryan, and Jason Grengs, "Allergen Levels in Inner City Homes: Baseline Concentrations and Evaluation of Intervention Effectiveness," Journal of Exposure Science and Environmental Epidemiology 18 (2008): 430-440.

A. Sherriff, A. Farrow, J. Golding, the ALSPAC Study Team, and J. Henderson. Frequent use of chemical household products is associated with persistent wheezing in preschool children. Thorax 60 (2205): 45-49.

United States Department of Housing and Urban Development (U.S. HUD). HUD's Healthy Homes Initiative. <http:// www.hud.gov/offices/lead/hhi/index.cfm > (Last accessed on December 8, 2008).
Shobha Srinivasan, Liam R. O'Fallon, and Allen Dearry, "Healthy People: Initiating a Research Agenda on the Built Environment and Public Health," American Journal of Public Health 93 (Sep 2003): 1446-1450.

Liam R. O'Fallon and Allen Dearry, “Community-Based Participatory Research As a Tool to Advance Environmental Health Sciences," Environmental Health Perspectives 110 (Apr 2002): 155-159.

Barbara A. Israel, Amy J. Schulz, Edith A. Parker and Adam B. Becker, "Review of Community-Based Research: Assessing Partnership Approaches to Improve Public Health," Annual Review of Public Health 19 (1998): 173-202. Kevin O'Neill, Kara J. Williams, and Vivian Reznik, “Engaging Latino Residents to Build a Healthier Community in Mid-City San Diego," American Journal of Preventive Medicine 34 (Mar 2008): S36-S41.

Stephanie A. Farquhar, Nargess Shadbeh, Julie Samples, Santiago Ventura, and Nancy Goff, "Occupational Conditions and Well-Being of Indigenous Farmworkers," American Journal of Public Health 98 (Nov 2008): 1956-1959.

Oregon Asthma Program, Office of Disease Prevention and Epidemiology, Public Health Services, Oregon Department of Human Services. "Oregon Surveillance Summary Report," August 2006: 8.

Jean-Francois Etter and Thomas V. Perneger, "Snowball sampling by mail: application to a survey of smokers in the general population," International Journal of Epidemiology 29 (2000): 43-38.

United States Census Bureau. State and County QuickFacts. $<$ http://quickfacts.census.gov/qfd/states/41/4159000. html $>$. (Last accessed on April 28, 2009).

Priscilla R. Ulin, Elizabeth T. Robinson, and Elizabeth E. Tolley. Qualitative Methods in Public Health: A Field Guide for Applied Research. (Jossey-Bass, 2004).

Robert Putnam. Bowling Alone: The Collapse and Revival of American Community. (Simon \& Schuster, 2000).

Address correspondence to: Ian Blazina

Portland State University School of Community Health

506 S.W. Mill St., \#450

Portland, OR 97201

E-mail: iblazina@pdx.edu 
